\title{
Bayesian Prediction of Mean Indoor Radon Concentrations for Minnesota Counties
}

\author{
P.N. Price \\ A. V. Nero \\ A. Gelman' \\ Energy and Environment Division \\ Ernest Orlando Lawrence Berkeley National Laboratory \\ University of California \\ Berkeley, CA 94720 \\ 'Department of Statistics \\ University of California \\ Berkeley, CA 94720
}

February 1996

This work was supported by the Director, Office of Energy Research, Office of Health and

Environmental Research, Human Health and Life Sciences Research Division of the U.S. Department of Energy (DOE) under Contract DE-AC03-76SF00098. 


\section{DISCLAIMER}

This document was prepared as an account of work sponsored by the United States Government. While this document is believed to contain correct information, neither the United States Government nor any agency thereof, nor the Regents of the University of California, nor any of their employees, makes any warranty, express or implied, or assumes any legal responsibillty for the accuracy, completeness, or usefulness of any information, apparatus, product, or process disclosed, or represents that its use would not infringe privately owned rights. Reference herein to any specific commerclal product, process, or service by its trade name, trademark, manufacturer, or otherwise, does not necessarily constitute or imply its endorsement, recommendation, or favoring by the United States Government or any agency thereof, or the Regents of the University of Califomia. The views and opinions of authors expressed herein do not necessarily state or reflect those of the United States Govemment or any agency thereof or the Regents of the University of California. 


\begin{abstract}
Past efforts to identify areas with higher thas average indoor radon concentrations by examining the statistical relationship between lacal mean concentrations and physical parameters such as the soil radium concentration have been hampered by the variation in local means caused by the small number of homes monitored in most areas. In this paper, indoor radon data from a survey in Minmesota are analyzed to minimize the effect of finite sample size within counties, to determine the true county-to-county variation of indoor radon concentrations in the state, and to find the extent to which this variation is explained by the variation in surficial radium concentration among counties. The analysis uses hierarchical modeling, in which some parameters of interest (such as county geometric mean (GM) radon concentrations) are assumed to be drawn from a single population, for which the distributional parameters are estimated from the data. Extensions of this technique, known as a random effects regression and mixed effects regression, are used to determine the relationship be tween predictive variables and indoor radon concentrations; the results are used to refine the predictions of each county's racton levels, resulting in a great decrease in uncertainty. The true county-to-county variation of GM radon levels is found to be substantially less than the county-to-county variation of the observed GMs, much of which is due to the small sample size in each county. The variation in the logarithm of surficial radium content is shown to explain approximately $80 \%$ of the variation of the logarithm of GM radon concentration among counties. The influences of housing and measurement factors, such as whether the monitored bome has a basement and whether the measurement was made in a basement, are also discussed. The statistical method can be used to predict mean radon concentrations, or applied to other geographically distributed environmental parameters.
\end{abstract}




\section{Introduction}

The overall U.S. distribution of indoor radon concentrations is a mixture of subsidiary local distributions that are approximately lognormal [Nero et al. 1990]. The variation in the geometric means (GMs) among county-sized areas is generally much greater than the variation of geometric standard deviations (GSDs), so that most high-radon homes are located in areas with relatively high GMs. Identifying such areas is thus a useful step towards focusing efforts to locate homes with indoor radon levels much higher than average.

In 1987-88, the Mimnesota Department of Health conducted a radon survey as part of U.S. Environmental Protection Agency's State/EPA Residential Radon Survey (SRRS) program [Tate et ai. 1988, White et al. 1992, Alexander et al. 1994]. The results indicate that indoor radon levels in Minnesota are higher than is typical in the U.S., and that there is significant variation of radon concentrations amoug the counties in the state. Earlier axtalysis [Nero et al. 1994] using ordinary regression techniques indicated that much of the variation in county GM indoar radon concentration could be predicted from surficial soil radium data obtained from the National Uranium Resource Evaluation (NURE). That analysis, as well as accurate prediction of individial county GMs, was hampered by uncertainties in county GMs due to small sampte sizes in most counties.

The present paper develops an improved statistical approach, again using the SRRS survey data from Minnesota as a demonstration. The analysis is performed in several parts, with the goal of introducing the ube of Bayesian random effects regressions as a way of determining the approximate underlying true distribution of county radon concentrations by minimizing effects of small sanple size.

The Minnesota data include measurements made in a stratified random sample of 919 owner-occupied ground-contact homes in Minnesota, performed with a "screening" protocol: a two- to four-day, winter charcoal-canister measurement was taken, usually in the lowest level of each home. The survey was conducted primarily with the goal of determining 
the overall screening radon distribution in the state. In addition to the measured radon concentration, data collected on each home include: the county in which the home sits, whether or not the home has a basment, whether the home was "single-family" (as opposed to a duplex, condominium, etc.), what room the measurement was made in (family room, dining room, etcl, and on what floor of the home the measurement was made. We use the screening data because they are available and can be expected to exhibit roughly the same spatial distribution as would data from long-term monitoring in living areas. Locating areas that have generally high long-term living-area radon concentrations would require long-term measurement data, either to supplant or to normalize the screening data.

The survey used a population-based stratification scheme to choose the number of participants per county. Adjustments were made to increase the sampling rate of expected high-radon counties and of low-population counties [Wirth 1992], but the distribution of measurements by county is extremely uneven: some counties had over 100 measurements, while other counties had few or none at afl. Thus any attempt to use the data to determine parameters describing county radon concentrations-such as the geometric mean radon concentration for each county-must contend with the effects of small smple size. The uncertainty due to small sample size also confounds analysis to find the relationship between county radon concentrations and physical factors such as geologic or soil information.

In this paper, we use the survey data to answer several questions:

1. What is the best estimate and uncertainty of each county's true geometric mean of radon screening measurements? By "true GM", we mean the GM that would have been obtained if every eligible home in the county had been measured with the survey protocol, and if measurement error due to background subtraction (discussed below) were eliminated.

2. How much of the county-to-county variation can be explained by the variation in surficial radium concentration from the National Uranium Resouce Evaluation? 
3. Some of the observed variation between county radon concentrations is probably due to differences in known house construction paramęters and measurement procedures (such as whether the home has a basement, and whether the measurement was made in a basement). How can we discoves the county-to-county variation that remains when these effects are removed?

We use regression techniques known as "random effects regression" and "mixed effects regression" to answer these questions. Although such techniques have been used in other fields for at least 15 years, we are not aware of their prevjous use in characterizing radon distributions or other environmental parameters. The procedures applied here are particularly useful when attempting to estimate parameters (such as county geometric means) based on sparse data.

A complete discussion of the mathematical details of hierarchical models and random effects regression is beyond the scope of this paper. Discussion of Bayesian hierarchical modeling in general can be fouad in Lindley and Smith 1972, Box and Tiao 1973, Bryk and Raudenbush 1992, or Gelman et al. 1995. Computational details can be found in Gelman et al. 1995 and Boscardin and Gelman 1996. Since these methodg have not yet become as ubiquitous as more familiar tools such as contentional regressions, we discuss them briefiy here in the context of the current problem, rather than simply presenting the results.

\section{The Minnesota Screening Data.}

Figure 1 shows a histogram of the radon concentrations reported from the state radon survey [Wirth 1992], weighted according to the sampling weights reported in the data set. A lognormal curve with $\mathrm{GM}=132 \mathrm{~Bq} / \mathrm{m}^{3}(3.6 \mathrm{pCj} / \mathrm{L})$ and $\mathrm{GSD}=2.18$ has been superimposed on the data. The observed radon distribution in the state as a whole is nearly consistent with a lognormal distribution. The important exception for our purposes is the presence of 
a few too many extremely low radon concentrations (affecting the lowest bin in the linear plot of Fig. 1), which sikews the calculation of geometric mean concentrations. Indeed, some of the reported radon concentrations are zero; in other state surveys, using similar protocols, negative radon concentrations have been reported. The distribution above about $40 \mathrm{Bg} / \mathrm{m}^{\mathrm{s}}$ appears almost perfectly lognormal.

The excess of low radon concentration measurements is consistent with being due to statistical errors in background subtraction: in determining radon levels, an expected number of background counts is subtracted from the observed number of total ractioactive decays. The number of radioactive decays exceeding the expected background count is ascribed to radon. Since the actual number of background counts varies statistically around the expected number, the number of counts attributed to radon (and thus the calculated radon concentfation) will differ from the actual number by a small amount (typically equivalent to a few $\mathrm{Bg} / \mathrm{m}^{3}$ ). This phenomenon can have a large relative effect when the actual radon concentration is small; indeed, it can lead to megative reported concentrations.

When the reported value is extremely small, it is almost certain that the true value is higher than the reported value; however, the exact magnitude of this effect is uniknown. We cannot simply discard the problematic points, since the low reported values really do occur in low-radon homes. If we were interested only in estimating distribution parameters for aggregated data, such as the geometric mean and geometric standard deviation, we could use a censored makimum likelihood estimate [Harter et al. 1966] with a censoring threshold set high enough to exclude the problematic points-that is, at 5 to $10 \mathrm{~Bq} / \mathrm{m}^{3}$. However, in the present paper we wish to perform analyses at the level of individual homes rather than county aggregates ${ }_{1}$ so distribution estimates are not suficient.

Since incorrect extrenely low values can cause problems, we have adjusted all of the low values upwards slightly with the extremely low values brougit up the most and the values above $50 \mathrm{~Bq} / \mathrm{m}^{3}$ essentially unaffected. 
The empirical adjustment we used to convert the reported radon concentration $C_{\mathrm{fth}}^{\text {meas }}$ to a new value $C_{\mathrm{R} n}^{\text {new }}$ was

$$
C_{\mathrm{RL}}^{\text {qew }}=\frac{C_{\mathrm{Rn}}^{\text {meas }}}{2}+\sqrt{\frac{\left(C_{\mathrm{RI}}^{\text {meas }}\right)^{2}}{4}+D^{2}}
$$

with $D=9.25 \mathrm{~Bq} / \mathrm{m}^{3}(0.25 \mathrm{pCl} / \mathrm{L})$, which was found to malee the entire digtribution appear nearly lognormal even for low radon levels. We do not claim that this equation has any underlying physical validity-it is merely a convenient one-parameter correction that adjusts very low values upwarọs very slightly in absolute terms, while leaving higher values vittually unchanged: a measured value of $0.00 \mathrm{~Bq} / \mathrm{m}^{3}$ is converted to $9.25 \mathrm{~Bq} / \mathrm{m}^{3}$, while a measured value of $20 \mathrm{~Bq} / \mathrm{m}^{3}$ is converted to $23.6 \mathrm{Bag} / \mathrm{m}^{3}$. Only a few measurements are affected substantially: of the 919 reported values, only 13 are below $20 \mathrm{Ba} / \mathrm{m}^{3}$. In this paper all of our discuksion of observed radon concentrations refers to the adjusted values $C_{\mathrm{R} r}^{\mathrm{new}}$, hereafter referred to simply as $C_{\mathrm{R} n}$, rather than the measured values. The results presented here are quite insensitive to the exact value of $D$, as long as it is above about 5 $\mathrm{Bq} / \mathrm{m}^{3}$. Mean outdoor concentrations are typically 5 to $10 \mathrm{Bg} / \mathrm{m}^{3}$ [Gesell 1983 ], so a value around $10 \mathrm{~Bq} / \mathrm{m}^{3}$ is a reasonable lower bounds for actual indoor radon concentrations. In addition, county GMs calculated with the adjusted values of $C_{\mathrm{Rn}}$ are in good agreement with the censored maximum likelihood estimates for the counties.

In addition to the statewide distribution of radon measurements being nearly lognormal, the observed distributions within the individual well-sampled counties are also approximately lognormal. Also, it has previousiy been noted that radon distributions in county-sized areas tend to be approximately lognormally distributed [Nero et al. 1986, Dudney et al. 1992). (However, see Cohen 1985, White et al. 1992, and Janssen et al. 1992 for some discussion and counterexamples.) For the present paper we have chosen to model the within-county distribution of radon measurements as lognormal.

In order to characterize a lognormal distribution, both the GM of the distribution and the geometric standard deviation (GSD) must be known. In Minnesota, all of the counties 
with more than 20 observations have observed GSDs between 1.8 and 2.35 . The observed variability in GSDs is only slightly greater than would be expected if all of the counties have the same true GSD (equal to about 2.1).

\section{Calculation of Posterior Estimates for the County GMs.}

We focus on predicting county GMs, for two reasons. First, since within-county distributions are approxirnately lognormal and the GSDs for all of the counties are about the same, knowledge of the GMs completely characterizes the distribution within counties. Furthermore, models are constructed in log space, which makes it computationally easier to predict GMs.

For simplicity in this section we ignore the explanatory variables related to soil radium concentration and to housing type, and discuss only the county geometric mean radon concentrations; use of the explanatory variables will be discussed in the next section.

We wish to use the observed county GMs to try to predict the true county GMs lof "screening" radon conceatrations). One approach is to use the observed GM as a direct prediction of the true GM (that is, to take $\mathrm{GM}^{\mathrm{pred}}=\mathrm{GM}^{\mathrm{obs}}$ ), but this has at least one serious drawback: it leads to a distribution of predicted GMs that is almost certain to be much wider than the distribution of true GMs, because of the effect of finite sample size. Given the small number of observations in most counties, some high-radon counties will happen to yield observed GMs even higher than their true GMs, and some low-radon counties will happen to yield GMs even lower than their true GMs. Imagine, for example, the effect of finite sample size on a group of counties with exactly the same true GM: the measured GMs will be spread about the true GM, with the degree of spread depending on the number of observations in each county.

All of our questions about the true county GMs and the overall distribution of county GMs would be easily answered if a large amount of data were available for each county. 
Unfortunately, about twenty observations are needed to determine a county GM with a standard error of twenty percent, while the median number of observations per county in Minnesota is only five. Much of the variation in observed county radon levels is certainly due to the effects of the small sample size in most counties. For example, consider Lac Qui Parle County: this county has only two observations, and the GM of the observations is about 500 $\mathrm{Bq} / \mathrm{m}^{3}$. This $\mathrm{GM}$ is considerably higher than the GMs of well-sampled counties (e.g. those with more than fifteen observations), all of which lie between 75 and $150 \mathrm{Bg} / \mathrm{m}^{3}$. It seems likely that the trute GM of Lac Qui Parle County is considerably lower than $500 \mathrm{~Bq} / \mathrm{m}^{3}$, and that the monitored homes from that county simply happened to have unusually high radon levels (at least over the days they were tested). How, then, can we obtain statistically well-founded predictions of the actual county GMs that adjust for the variation due to finite sample size?

A reasonable answer to this question is provided by a bierarchical model: we assume the true county GMs are drawn from some distribution of "possible" county GMs, and that the parameters of this distribution can be estimated from the data. For instance, suppose we knew the true GM for 86 counties, randomly selected from the 87 counties in Minnesota. Furthermore, suppose these 86 values were found to be approximately lognormally distributed with a geometric mean of $145 \mathrm{~Bq} / \mathrm{m}^{3}$ and a geometric standard deviation of 1.4. Then, even if we had no observations from the missing county, it would be reasonable to guess that its true GM is likely to fall between $75 \mathrm{~Bq} / \mathrm{m}^{3}$ and $285 \mathrm{~Bq} / \mathrm{m}^{3}$ (two GSDs below and above the GM of the county GMs, respectively) with about $05 \%$ certainty.

In the hypothetical situation described here, we have substantial knowledge of the range in which the missing county's true GM is likely to fall etren though we have no meastrements at all from that county. This conclusion relies on the plausible assumption that the GM of the missing county is drawn from the same distribution as the GMs of the known counties; we would certainly be surprised if the GM of the missing county were later found to be, 
say, $800 \mathrm{~Bq} / \mathrm{m}^{3}$ or $1 \mathrm{~Bq} / \mathrm{m}^{3}$. In conventional statistical notation, with $\theta$ representing the true value of the logarithm of the county's geometric mean radon concentration, knowiedge of the distribution from which the missing county's $\log (G M)$ is drawn would be written:

$$
p(\theta)=N\left(\mu, \sigma^{2}\right)
$$

indicating that the probability of obtaining a particular value of $\theta$ is normally distributed about $\mu$ [equal to $\log \left(145 \mathrm{~Bq} / \mathrm{m}^{3}\right)$ in the current example] with standard deviation $\sigma$ [equal to $\log (1.4)$ in the current example]. In such a case, in which the distribution from which the missing county's GM is drawn is known, $p(\theta)$ is known as an informative prior distribution. The case of $\sigma^{2} \rightarrow \infty$, corresponding to a distribution of county GMs that has infinite variance, would be a roninformative prior distribution, indicating total ignorance of the likely range containing the missing county's true $\log (\mathrm{GM})$.

We wish to avoid the misconception that the assumption of a distribution from which parameters are drawn is equivalent to the assumption that the variation between counties is "random" rather than having some physical explanation-in fact all it means is that explanatory variables useful to predict the exact values are unknown for purposes of the analysis.

If we are now given some measurements from the missing county (in the form of a list $y$ ), Bayes's theorem [Bayes 1763] can be applied to determine a new estimate of the county's true GM. Bayes's theorem states that

$$
p(\theta \mid y)=\frac{p(\theta) p(y \mid \theta)}{p(y)}
$$

The notation $p(\theta \mid y)$ reads "the probability of $\theta$ given $y$ "; in the current context it represents the probability that "the true mean is $\theta$ ", given "the set of observations $y \cdot{ }^{n}$ In order to apply this equation, we must have some way of calculating $p(y \mid \theta)$, known as the likelihood. The likelihood $p(y \mid \theta)$ is the probability that the values $y$ would have been observed, if the true value of $\log (\mathrm{GM})$ is $\theta$. In order to evaluate this likelihood, we require a statistical model for 
the distribution of observations within a county. The value of $\theta$ that maximizes Equation 3 can be thought of as a "best guess" at the true value of $\theta$. (Note that the denominator of Eq. 3 is independent of $\theta$; in practice we need not evaluate it, since it merely provides a normalization factor.) Generaliy, we are not interested only in the best guess but also in the uncertainty-the range of values of $\theta$ that are reasonably consistent with the observations $y$ and with our prior knowledge of the possible values of $\theta$.

Usually, as in the case of the current Minnesota data set, we do not have direct knowledge of the true distribution of county GMs. There are only eight Minnessota counties for which more than twenty observations were made, so for most Minnesota counties the true GM is quite uncertain.

The observed county GMs, however, are approximately lognormally distributed, and the distribution of measurements within each county is also approximately lognomal. We therefore select the following statistical model for the distribution of radon measurements:

1. The true county GMs are lognormally distributed: the values of $\log (G M)$ are drawn from a nocmal distribution with unknown mean $\mu$ and unknown variance $\sigma^{2}$, as in Eq. 2 .

2. The observations within a county are also lognormally distributed the logarithms of the observations are drawn from a normal distribution with a mean equal to the true value of $\log (G M)$ and unknown variance $\kappa^{2}$. For the purposes of the present analysis, $\kappa^{2}$ is assumed to be the same for all counties. This is equivalent to the assumption that all of the counties have the game GSD.

The true value of $\log (G M)$ for each county is the main parameter of interest. With the lognormality assumptions mentioned above, the application of Bayes's theorem (Eq. 3) yields a particularly simple result for the estimate of $\log (\mathrm{GM})$ for county $i$ : the most probable value of the true $\log (\mathrm{GM})$ is given by a weighted average between the observed 
value of $\log (\mathrm{GM})$ for the county and the 'grand mean' $\mu$ of the distribution from which all of the county $\log (G M)$ valtres are drawn, where the relative weights depend upon the number of observations $n_{i}$ in the county, and the variance estimates $\sigma^{2}$ and $\kappa^{2}$;

$$
\log \left(\mathrm{GM}_{i}^{\text {point estimate }}\right)=\frac{\left(1 / \sigma^{2}\right) \mu+\left(n_{i} / \kappa^{2}\right) \log \left(\mathrm{GM}_{i}^{\text {obs }}\right)}{\left(1 / \sigma^{2}\right)+\left(n_{i} / \kappa^{2}\right)}
$$

Equation 4 provides a point estimate of the true GM, but this estimate is uncertain: the probability distribution of the true value about this estimate, given $\mu_{1} \sigma^{2}$, and $n_{i} / \kappa^{2}$, is described by:

$$
p\left(\theta \mid \mu, \sigma^{2}, n_{i} / \kappa^{2}\right)=\mathrm{N}\left(\log \left(\mathrm{GM}_{i}^{\text {point gstimaks }}\right), V_{i}^{2}\right)
$$

where

$$
V_{i}^{2} \equiv\left(1 / \sigma^{2}+n_{i} / \kappa^{2}\right)^{-1}
$$

Mathematically it's as though we already had some number (equal to $\kappa^{2} / \sigma^{2}$ ) of observations of $\log \left(C_{\mathrm{R}_{n}}\right)$ in each county, with the mean of the observations being $\mu$, before any actual observations were made.

In order to actualiy perform this adjustment, we need values for $\mu, \sigma$, and $\kappa$. These parameters are estimated from the data A point estimate for $\mu$ is provided by the mean of the observed county $\log (\mathrm{GM}) \mathrm{s}$, yielding a value $\mu \approx 4.96$ (in units of $\log \left(\mathrm{Ba} / \mathrm{m}^{3}\right)$ ). Approximate estimates for the true within-county variance $\kappa^{2} \approx 0.54$ and the true betweencounty variance $\sigma^{2} \approx 0.11$ are determined from an analysis of variance. These correspond to a within-county GSD of $\exp (\sqrt{0.54})=2.1$, and a distribution of true county GMs that has a GM of $\exp (\mu)=143 \mathrm{~Bq} / \mathrm{m}^{3}$ and a GSD of $\exp (\sqrt{0.11})=1.4$. The method of using point estimstes of parameters generated from the data themselves, and then using those estimates through Bayes's theorem to estimate quantities of interest, is sometimes referred to as an "empirical Bayes" method.

Although use of the point estimates for the model parameters leads to reasonable estimates of the county GMs, the resulting uncertainty estimates are too small, since they do 
not include the uncertainties in the model parameters themselves. For this reason, we do not restrict ourselves to point estimates of the values of the parameters; rather, we estimate the distribution of likely values for the parameters, then draw randomly from that distribution and use the resulting parameters in Eq. 5 to obtain an estimate for each county's true $\log (G M)$. Detaj]s of this so-called "full Bayes" procedure can be found in Gelman et al. (1995). The sampling procedure is repeated many times (1000 in the current case), with each set of paraneters yielding an estimate for each county's $\log (\mathrm{GM})$; the resulting distribution of $1000 \mathrm{GM}$ estimates for each county is spread over a range due to both the uncertainty in the true values of the parameters in the hierarchical model and the uncertainty due to the finite nurber of measurements (which would remain even if we knew the exact parameters of the distribution from which the county GMs are drawn). We select the mean of the 1000 estimates for each county as our "best guess", or posterior estimate, of the county's GM. The procedure described here can be carried out directly, or as a special case of a random effects regression, described in the next section.

Results for counties with more than five observations are shown in Figure 2, in which the posterior estimates of county GM and uncertainty (an exror bar containing the middle $50 \%$ of the posterior estimates for each county's GM when the sampling procedure described above is performed 1000 times) are plotted against the $G M$ of the measurements in the county. The points are plotted as numbers, with the number being the number of observations in the county. The distribution of posterior estimates of the GMs (shown on the abscissa) is much narrower than is the distribution of observed county GMs (on the ordinate), as expected. The mean estimate of $\kappa^{2}$ is 0.570 , corresponding to a within-county GSD of 2.13 . The mean estimate of $\mu$ is 4.95 , corresponding to a GM of $141 \mathrm{~Bq} / \mathrm{m}^{3}$ for the distribution of county GMs; and the mean estimate of $\sigma^{2}$ is 0.097 , corresponding to a GSD of 1.37 for the distribution of county GMs.

Lac Qui Parle County, with only two observations yielding an observed GM of 498 
$\mathrm{Bq} / \mathrm{m}^{3}$, has a mean posterior estimate of $196 \mathrm{Bg} / \mathrm{m}^{3}$, although the true value may be as low as $213 \mathrm{~Bq} / \mathrm{m}^{3}$ or as high as $342 \mathrm{~Bq} / \mathrm{m}^{3}$ (the 2.5 and 97.5 percent posterior interva) limits, respectively). The results appear reasonable, although it may be surprising how large the effect of finite sample size is estimated to be.

Interestingly, although Lac Qui Parle County had the highest observed GM (498 Bq/ $\left.{ }^{3}\right)$, it does not have the highest "best guess" GM, losing out to Blue Earth County, which had an observed GM of $250 \mathrm{Ba} / \mathrm{m}^{3}$ and has a posterior estimate of $210 \mathrm{~Bq} / \mathrm{m}^{3}$. This is a consequence of the fact that Blue Earth County had many more observations than Lac Qui Parle County (14 as opposed to 2). Simply put, the distribution of observed county GMs suggests that most true county GMs fall in the range between 75 to $150 \mathrm{~Bq} / \mathrm{m}^{3}$, and there is more evidence that Blue Earth County falls beyond that range than there is evidence that Lac Qui Parie does so.

The predictions from the model seem ressonable, but that alone is not, of course, suffcient to give us confidence in them. Several validation checks have been carried out. One type of check concerns the degree of agreement between the model predictions and the observations. For example, given the posterior estimates of the county GMs, how often would we expect to see an observed GM as high as $500 \mathrm{~Bq} / \mathrm{m}^{3}$ ? To answer this question, we start with the posterior estimates for the county GMs, then simulate the sampling procedure (by selecting the appropriate number of simulated "observations" from each county's assumed distribution) and examine the resulting "observations" to see how they compare statistically with the actual observations. Repeated simulation of the sampling procedure, using the actual number of observations in each county yjelds at least one county with an "observed" county GM higher than $500 \mathrm{~Bq} / \mathrm{m}^{3}$ about $30 \%$ of the time, so such a high observation clearly does not viokate the conclusions based on the model.

Another type of validation check that we performed was to create a validation data set by discasding a random $90 \%$ of the data from the four counties with more than 50 
observations. Complete data from all of the other counties, plus the reduced data from those four counties, were then used to fit the model again. The predictions for those four counties were then compared to the true GMs as known from the complete data for those counties. This sampling/predieting procedure was carried out many times. The model validated well, in the sense that the true values for the well-sampled counties fell within one standard error of the estimate in about $68 \%$ of the tests, and within two standard errors in about $95 \%$ of the tests.

Although the statistical model discussed above does validate well and does appeas to provide better estimates for each county's GM, the estimates are still fairly uncertain, especially for the many poorly-sampled counties. In the next section, we discuss the use of predictive variables to improve the predictions for the county GMs.

\section{Regression prediction of the county GMs.}

It has been noted previously [Nero et al. 1994] that much of the county-to-county variation in Minnesota's indoor radon levels (as measured by the GM) can be explained by variation in surflcial radium content as determined by the aerometric survey conducted as part of the National Uranium Resource Evaluation (NURE). The NURE survey measured radiation spectra along flight lines spaced at 6 to 12 miles across the U.S. These data were processed using various extrapolation and smoothing schemes [Duval et al. 1989] to produce a nationwide map of equivalent surface uranium concentration, which was used to estimate the concentration of radium, a uranium decay product. Previous work [Moed et al. 1985, Revzan et al. 1988, Gundergen et al. 1991, Jackson 1992, Nero et al. 1994] has used aerial radiometric survey data to predict distributions of radon concentration measurements or to locate areas with high radon "potential". We have aggregated the NURE data of Duval et al. (1989) to generate average surface radium concentration (expressed in equivalent ppm of radium) by county; in Minnesota, the resulting NURE values range from $0.14 \mathrm{ppm}$ to 
$0.57 \mathrm{ppm}$, with a median of $0.39 \mathrm{ppm}$.

Figure 3 plots the GM of the radon concentration measurements in each county versus the GM predicted by a conventional weighted linear regression of the logarithm of each county's GM on the logarithm of the county-averaged NURE value; conventional error bars (1 standard error) are plotted for the observed GMs, based on the approximation that the true GSD of each county is 2.1. Only counties with more than five observations are shown, to awoid clutter. Note that over $60 \%$ of the error bars cross the 45-degree line, indicating that the observations vary from the predictions only slightiy more than the expected variation due to small sample sizes if the NURE predictions were exactly equal to the true GMs. For the $\log$-space conventional linear regression the value of $R^{2}$, a standard measure of model fit, is 0.58 for the counties shown here. However, this figure substantialiy underestimates the real predictive ability of NURE in this case, since much of the variation between predicted and observed GMs is certainly due to small-sample noise rather than differences between the true GMs and their predicted values.

In this section, we discuss a procedure to predict the true county GM using both the observations and the fitted results for the county. This procedure provides a method of using both observational data and explanatory variables together in a statistically consistent way in order to predict each county's true GM. The statistical model we wish to apply is defined as tollows:

1. The true values of $\log (\mathrm{GM})$ for each county are drawn from a normal distribution with a mean equal to the predicted value of $\log (G M)$ based on a regression, with unknown variance $\sigma^{2}$, so that for county ?

$$
\log \left(G M_{2}\right)=\beta_{0}+\beta_{N U R E} \log \left(\mathrm{NURE}_{3}\right)+\delta_{2}
$$

where $p\left(\delta_{z}\right)=\mathrm{N}\left(0_{1}, \sigma^{2}\right) ;$ or equivalently, with $\theta_{2}=\log \left(\mathrm{GM}_{4}\right)$

$$
p\left(\theta_{t} \mid \mathrm{NURE}_{\mathrm{z}}\right)=N\left(\beta_{0}+\beta_{\mathrm{NURE}} \log \left(\mathrm{NURE}_{\mathrm{s}}\right), \sigma^{2}\right)
$$


The parameter $\sigma^{2}$ does not have the same value as the $\sigma^{2}$ in the previous section unless $\beta_{\mathrm{NURE}} \equiv 0$, in which case the model reduces to the model in the previous section.

2. We number the 919 radon measurements with the index $\{j\}$, and assume that the logarithm of observation $j$ within county $i$ is drawn from a normal distribution with a mean equal to the county's true $\log (\mathrm{GM})$, and with an unknown variance $\kappa^{2}$ assumed the same for all counties, so that

$$
p\left(\log \left(C_{\mathrm{Rn}}\right)_{j}\right)=\mathrm{N}\left(\log \left(\mathrm{G} M_{i}\right)_{1} \kappa^{2}\right)
$$

The parameters $\beta_{0:} \beta_{\mathrm{NURE}}, \sigma$, and $\kappa$ are again to be estimated from the data. A large value of $\sigma^{2}$ would indicate that NURE is a poor predictor of true county GMs, while a small value of $\sigma^{2}$ would indicate that the true county GMs are closely grouped around their NURE predictions.

A simple but imperfect estimate of $\sigma^{2}$ can be obtained as follows: regress observed $\log$ (GM) on $\log$ (NURE), then apply the hierarchical model described in the previous section to the residuals. This procedure is correct in spirit and provides a quick estimate of the true distribution of the residuals. However, this method yields confidence intervals that are too narrow, since it does not include the uncertainty in the regression coefficients themselves. Rather than present results of such an incomplete analysis, we will carry out a procedure, called "random effects regression", that takes into account all sources of uncertainty in the model parameters. Before describing random effects regressions, we first discuss the use of "dummy variables" in conventional linear regressions. In statistical regression, a dummy variable is used to indicate the presence or absence of a particular characteristic, or that the data are included or excluded from a particular class. For example, in the present case we create a dummy variable for each county in Minnesota ( 85 in all, if we include only the counties for which there is at least one measurement). Each of the 919 radon measurements 
$C_{\mathrm{R}, \mathrm{I}}$ is therefore associated with 85 dummy explanatory variables, all but one of which takes the value of zero; the value unity is assigned to the variable that denotes the county in which the measurerient was made.

A conventional linear regression of the values of $\log \left(C_{\mathrm{Rn}}\right)$ on these 85 dummy explanatory variables alone yields 85 regression coefficients, each of which is the mean of the observations of $\log \left(C_{\mathrm{Rn}}\right)$ in the indicated county. The hierarchical model introduced in section 3 can be reproduced by applying Bayes's theorem with the assumption that these regression coefficients are measurements with error of underlying "true parameters, which are drawn from a normal distribution.

The hierarchical regression model introduced in the present section can be applied also, and the uncertajnties properly estimated, by including another explanatory variable, in addition to the county dummy variables; for each of the 919 observations this variable takes the value of NURE averaged over the county that contains the observation. With NURE included as an explanatory variable, the values of $\{\delta\}$ from Eq. 7 , indicate the "true" residuals from the NURE regression (i.e. the difference between the true value of $\log \left(\mathrm{GM}_{i}\right)$ and the NURE predictions).

The difference between a county's true $\log (G M)$ and the regression prediction for the cotunty is referred to as the "county effect". Regression coefficients (such as county effects) that are assumed to be drawn from a common distribution are usuatly referred to as "random effects"; hence the name "random effects regression." When a model includes both conventional regression variables ("fixed effects") and random effects, it is called a "mixed effects model". All models discussed hereafter are mixed effects models. As before, the assumption that random effects are drawn from a common distribution does not imply that there is no reason that some of the county effects are large while others are small, merely that we have no information (other than the data being analyzed) that allows us to determine which counties have large effects and which don't. 
The mathematical detaits of performing a Bayesian mixed effects regression are rather involved-see the "Notes and Acknowledgements" section at the end of this paper. The basic ideas of the mixed effects regression are those discussed in the previous section: the conditional distributions of the parameters (regression coefficients and variance components) are calculated, and parameters are drawn from the calculated distribution. Where appropriate, a hierarchical model is assumed (as for the county effects). The procedure is repeated many times in order to obtain posterior intervals (conceptually similar to confidence intervals, in that they reflect the range in which the true value is likely to fall) on the parameters.

Using the model described by equations 7 and 9 above, we perform 1000 simulations to obtain 1000 estimates for each of the parameters: $\beta_{0}, \beta_{N U R E}, \kappa_{1} \sigma_{1}$ and each of the 85 values of $\delta_{i}$. The estimated county effects $\{\delta\}$ do double duty: they allow us to predict the county GMs, and they also provide a way of measuring the extent to which the other explanatory variables allow prediction of indoor radon levels. The extent to which NURE is a good predictor of the true county GMs can be gauged from the likely values of $\sigma$ : if $\sigma$ is small (and thus the county effects are all near zero), then NURE alone is enough to predict the GM of radon concentrations in a county from $\mathrm{Eq}$. 7. If $\sigma$ is large, then at least some of the individual county effects are large, and NURE alone is rot sufficient to obtain a good estinate of the county's true GM. Furthermore, $\sigma$ can be used to define a measure of model fit for the county radon levels that is analogous to $R^{2}$ : as in Bryk et al. (1992), we define an effective $R_{\text {eff }}^{2}$ as

$$
R_{\text {eff }}^{2} \equiv 1-\frac{\text { unexplained variance of true } \log (\mathrm{GM}) \text { values }}{\text { total variance of true } \log (\mathrm{GM}) \text { values }} \text {. }
$$

We do not know either the unexplained variance or the total variance of true values, but we do have estimates of exch: we obtain estimates of $\sigma^{2}$ from random effects regressions performed with and without NURE (or other explanatory variables), in both cases including the county dummy variables. The best estimate of $\sigma^{2}$ when only the county dummy variables are included provides us with an estimate of the true total variance of the county GMs, while 
the best estimate of $\sigma^{2}$ when dunmy variables and other variables are included provides us with an estimate of the unexplained variance. As long as only county-level variables are included, the estimate of $R_{\text {ef }}^{2}$ obtained this way will behave similarly to the conventional measure of $R^{2}$, in the sense that it will always increase (or remain constant) as additional variables are added. However, if the model contains individual-house variables, then the value of $R_{\text {eff }}^{2}$ can actually decrease as additional variables are added. An interesting and informative example is considered in the next section.

For the current case, with NURE included as the only explanatory variable, the mean posterior estimate of $\sigma^{2}$ is 0.019 . Combining this with the value of $\sigma^{2}=0.097$ obtained when only the county effects are included, we obtain the an estimated value of $R_{\mathrm{eff}}^{2}=0.80_{\mathrm{i}}$ our best estimate is that $\log (\mathrm{NURE})$ explains $80 \%$ of the county-to-county variation in $\log (\mathrm{GM})$. In terms of determining a county's $\log (\mathrm{GM})$, knowledge of the county's NURE value is "worth" an extra $\kappa^{2} / \sigma^{2} \approx 30$ observations in each county (see the comments following Eq. 6).

The ability of NURE to predict county GMs so well appears to be unique to the state of Minnesota - in the several other states of the U.S. that we have examined, NURE has lower predictive power, with $\log$ (NURE) typically explaining about $30 \%$ to $65 \%$ of the variation in the logarithm of the county GMs.

The coefficient of $\log (\mathrm{NURE})$ in Eq. 7 is estimated to be $b=0.711$, with $95 \%$ posterior bounds of 0.537 and 0.880 . Since a coefficient of $\log (N U R E)$ different from unity implies (after transforming back from log space) a nonlinear relationship between county soil radium concentration and county indoor radon concentration, this resuit may seem peculiar: at least for individual homes, physical models suggest the indoor concentration should be approximately proportional to the radium concentration in the surrounding soil.

Several factors may contribute to a non-linear relationship between county-average NURE and the indoos radon concentration measurements. First, the use of county-average 
NURE would be completely appropriate only if homes in each county are uniformly distributed over the entire area of the county. But since homes are clustered within counties, it's likely that in some counties homes are more concentrated in areas with radium concentrations above the county average, while in others they're more concentrated in low-radium areas. A consequence of such an occurrence would be a decreased coefficient of $\log$ (NURE), through the regression effect (se Price 1995, for example). Furthermore,the NURE measurements are subject to errors due to factors such as soil mojsture content that are likely to affect indoor radon concentrations [Duval et al. 1989, Schumann et al. 1994]. Given these facts, a coefficient different from unity in the regression is not surprising.

Figure 4 shows the result of performing the mixed effects regression; as in Fig. 3, only counties with more than 5 observations have been plotted. The posterior predicted GM for each county has been plotted with a square, as a function of the prediction based on a conventional regression on $\log (\mathrm{NURE})$; thus, if the posterior prediction and the conventional regression prediction agreed perfectly, the squares would be plotted on the 45-degree line on the figure. The GM of observations in each county has been plotted with a point (the same as Figure 3, except that that error bars are not shown). The position of each square represents a sort of weighted average between the observed GM and the GM predicted from a conventional regression on $\log (\mathrm{NURE})$, with the relative weighting determined from the data.

For counties with many observations the posterior estimate is always very close to the observed GM, while for counties with fewer observations the final estimate can differ substantially from the observed GM. Most of the final estimates are very close to the regression line-there is strong evidence that NURE explains almost all of the county-to-county variation in radon levels in Minnesota. However, as noted previously the distribution within each county is quite broad: the best estimate of $k$ is 0.76 , corresponding to a GSD of 2.1 .

Table 1 presents results for each county in Minnesota (jncluding the two counties with 
no observations): the number of observations in the county, the GM of the observations, the predicted GM from a comventional linear regression of county $\log (\mathrm{GM})$ on county $\log$ (NURE) alone, and the posterior estimate and uncertainty (one standard error) of the county's true GM, based on the mixed effects regression described above. The 'uncertainty' is an approximation, treating the posterior GM estimates as if they were normally distributed. If more accurate summaries of the uncertainties are desired, posterior intervals can be determined directly from the distribution of 1000 posterior estimates from esch county.

Figure 5 displays histograms of the distribution of observed and estimated county GMs. Each county is represented by a number indicating the number of observations in the county, and each number is stacked in the column appropriate to the county GM radon concentration. Thus the "105" in the $120-140 \mathrm{~Bq} / \mathrm{m}^{3}$ interval does not represent a county with 105 observations all of which fell in that interval; the observations from that county are spread over a very large range, (from $9.25 \mathrm{~Bq} / \mathrm{m}^{3}$ to $888 \mathrm{~Bq} / \mathrm{m}^{3}$, as it happens), with a GM that falls in the range $120-140$. Note that all of the counties with observed GMs over $250 \mathrm{~Bq} / \mathrm{m}^{3}$ have 5 or fewer observations. The distribution of predicted GMs is much tìghter than the distribution of observed GMs - there is no convincing evidence that any of the true GMs are as high as $250 \mathrm{~Bq} / \mathrm{m}^{3}$, although some county predictions barely include $250 \mathrm{~Bq} / \mathrm{m}^{3}$ within two standard errors. The distribution of true GMs is somewhat broader than the distribution of predicted GMs that is shown, since the true GMs are distributed about the predicted values, with standard errors given in Table 1.

\section{Including additional explanatory variables.}

In addition to the measured indoor radon concentration and the county NURE measurement, we have some information on each home in the survey: does the home have a basement, and, if so, was the measurement made in the basement. The presence of a basement might be expected to have some effect even on first-floor indoor radon measurements, and 
certainly measurements made in basements are expected to be higher than measurements made on the first floor. There are two substantive reasons that we wish to take account of the basement and toor effects.

First, we are interested in the magnitude of the coefficients themselves: how much higher are messurements made in the basement than those made on the first floor?

Second, what are the county effects after controlling for the floor effect in the homes in each county? For example, do the low-radon counties have lower radon levels merely because they have more non-basement homes?

As an initial attempt to answer these questions, we introduce three individual-home explanatory dummy variables. One variable $(\gamma)$ indicates homes that have basements and were monitored in the basement, one $(\phi)$ indicates homes that have basements but were monitored on the first foor, and one ( $\nu$ ) indicates homes without basements. Most homes769 of the 919 homes tested-have a basement and were monitored in the basement. Of the remaining 150 homes, 92 have a basement but were monitored upstairs, while the rest do not have a basement.

The model is defined as follows. For a home $j$ in county $i$, the probability of obtaining a given observation is given by

$$
p\left(\log \left(C_{\mathrm{RD}}\right)_{j}\right)=\mathrm{N}\left(\beta_{\mathrm{NURE}} \log \left(\mathrm{NURE}_{\mathrm{i}}\right)+\beta_{\mathrm{bb}} \gamma_{j}+\beta_{\mathrm{b} 1} \phi_{j}+\beta_{\mathrm{nob}} \nu_{j}+\delta_{i}, \kappa^{2}\right)
$$

Here $\beta_{b b}$ is the effect associated with a basement home that is monitored in the basement; $\beta_{\mathrm{b} 1}$ is the effect for a basement home monitored on the first floor, and $\beta_{\text {nob }}$ is the effect for a home without a basement. As before, the county effects $\left\{\delta_{i}\right\}$ measure the extent to which the explanatory variables in the linear model fail to explain all of the countyto-county variation in radon concentrations, and are assumed to be normally distributed. If NURE and the bousing dummy variables were sufficient to predict the distribution of measured values in homes in different counties, with no remaining evidence of unexplained between-county variation, then the county effects would be near zero. Coefficient estimates 
and variance estimates are presented in Table 2, along with estimates from other models discussed below. The coefficient estimates all happen to have standard errors of about \pm 0.1 or so, except for the coefficient associated with the fraction of homes that do not have basements (discussed below), which has a standard error of about \pm 0.3 .

The model including individual-house explanatory variables does not allow direct prediction of the county GMs, since Eq. 11 does not contain only county-level variables. Essentially, we obtain separate estimates for each county for homes in three different categories: homes with basements in which the Rn levels were measured in the basement, homes without basements, and homes with basements but in which the monitoring was nevertheless performed on the first floor. Use of these results to estimate the true county GMs would require knowledge of the distribution of housing types by county. We have not attempted to model the distribution of housing types. We perform the individual-house analysis only to illustrate that the techniques described in this paper can handle both individual and county-level data.

An interesting result of this regression is that the variance of the counby effects goes up compared with the previous, NURE-only regression. How can this happen? Consider Roseau county. The NURE value, when used in the conventional NURE-only regression, predicts the average value of $\log \left(C_{\text {th }}\right)$ for homes in the county should be about $\log (126$ $\left.\mathrm{Bq} / \mathrm{m}^{3}\right)$, in good agreement with the observed value of $\log \left(131 \mathrm{~Bq} / \mathrm{m}^{3}\right)$. Hodrever, in 5 of the 14 monitored houses in Roseau county, the measurement was made on the first floor of a home rather than in a basement. Since first-floor measurements are expected (based on the full regression) to be about half as high as basement levels, and since $5 / 14$ represents a much lacger fraction of non-basement homes than is typical in counties in Minnesota the full regression prediction for the homes in Roseau county is now much too low, so the county effect estimate for this county must be made fairly large in order to bring the prediction into agreement with the observations. 
The increase of the size of the county effects when additional data are included indicates some violation of the model. In this case, it indicates that there is some difference between counties with many non-basement homes and those with few non-basement homessome diflerence that affects radon levels. For example, we speculate that counties with generally high soil moisture may have fewer basement homes, and the soil moisture may also influence indoor tadon concentrations (and perhaps the NURE observations as well [Duva] et al. 1989]).

To help resolve this issue, we add another county-level explanatory variable: observed fraction of non-basement homes. For all the homes in a colnty (whether or not they bave a basement) this variable takes the value of the fraction of survey homes in the county that do not have a basement. (We would prefer to use actual fraction of non-basement homes in the county, rather than observed fraction, which is subject to significant noise due to the omall number of observations in most counties. Unfortunately the actual fraction for each county is not available.) A sizeable coefticient for this variable would indicate that the fraction of non-basement homes is correlated with county radon levels, over and above the correlation due to the fact that levels in the measured homes depend upon whether the measurement was made in a basement or not.

Including the county-level non-basement fraction variable does decrease the magnitude of the county effects when individual-house basement categories are included (Model 5), although the county effects are still slightly smaller in the models that do not include individual-house variables.

\section{Spatial distribution of county effects.}

Thus far, we have not included any spatial information in our analysis. This fact does not invalidate any of the analyses discussed above; specifically, the estimates of the county effects (and the estimates of $\sigma$ ) are valid even though spatial information has not been included. 
Given these facts, there might seem to be no need to delve into the spatial relationships in the data.

However, there are pitfalls to blindly applying the regression results without regard to spatial concerns. For example, suppose we wish to use the NURE-only regression to predict the mean radon level in some group of counties. If these counties are selected at random across the state, there is no problem with combining the regression predictions for the individual counties to predict the geometric mean of the entire group, and the more counties that are included in the group, the lower the error in the estimated GM is likely to be. If, on the other hand, the counties were all selected from a particular region of the state, then the presence of spatial correlations in the county effects would lead to problems: our estimated group GM would be overcertain, unless we account for such correlation.

Also, spatial correlation in the county effects presents an opportunity: if there are some areas that are higher or lower in radon than predicted, even after controlling for the available explanatory variables, then the locations of these areas might suggest avenues of exploration to improve the models. In principle, even if no explanatory variables can be found that explain the spatial correlations, the presence of the correlations themselves can allow improvements in the accuracy and precision of the models by creating an explicitly spatial model. However, such in-depth analysis of the spatial correlations is beyond the scope of the present paper.

Instead, we display the estimated county effects from Model 5 on a map of Minnesota (Figure 6). The estimated county effects have been multiplied by 100 to avoid printing nnnecessary digits. Notice that there do seem to be patterns in the distribution of county effects; specifically, most of the large negative county effects occur in counties to the east of about 94 degrees longitude, while most of the large positive county effects occur to the west of that line. "Large" is only relative in this context-the county eftects with the largest magnitudes correspond to modifications from the ordinary regression predictions of only 
about $15 \%$, and most of the effects are much lower.

To remove the obvious east-west spatial trend, we added a "longitude" variable to the model. This county-level variable assigns to each data point the scaled longitude of the center of the county in which the house sits; the variable was defined as (longitude -97 ) $/ 7$, which is zero at the western edge of the state, and unity near the eastern edge. The resulting models (numbers 6-9 in Table 2) show a barely improved fit, as indicated by the decrease in $\sigma$. In addition, examination of the spatial distribution of the associated county effects revoals no obvious large-scale trends, although non-random clumps of positive or negative county effects can still be found. The negative coefficient of the longitude variable indicates that county mean radon concentrations tend to be lower in the eastern part of the state than would be predicted based on the other explanatory variables alone, and higher on the western part of the state. However, the effect is quite small, changing most

county posterior predicted GMs by a few $\mathrm{Bq} / \mathrm{m}^{3}$ in spite of the fact that the coefficient of the longitude variable is substantial: the effect of the sizeable coefficjent of the longitude variable is largely offset by the decrease in the coefficient of $\log$ (NURE), which is partially collinear with longitude (a correlation of $r=-0.35$ ).

In summary, although there is evidence for spatial variation in county GMs that is not explained by the inchuded explanatory variables, the effect of such unexplained variation on the predictions for the true county GMs is very small.

\section{Discussion and Conclusions.}

The models discussed above contain four variables believed to be directly related to indoor radon concentration measurements: NURE, which is a measure of surficial radium concentration; and the three housing variables, which are related to the coupling between soil-gas radon concentrations and the indoor radon concentration.

We have included two additional county-level variables in the model: observed fraction 
of non-basement homes, and county longitude. These variables are not directly related to indoor concentration measurements; to the extent that they increase the predictive value of the models, they must be proxy for other (presently unknown) variables.

Inclusion of the individual-house basement categories improves the withir-county fits, as indicated by the decrease in $\kappa$, although it does not decrease $\sigma$. Although including the basement categories does not result in lower county effects, it does lead to a slight decrease in the uncertainty of the jndividual county effect estimates-this is a small effect in most counties, but for a few coumties the uncertainty (the width of the $68 \%$ posterior intervals) decreases by $15 \%$ or more.

Which of the models discussed above should be preferred? The answer depends on the purpose of the analysis. For purposes of estimating the true county GM's in Minnesota; using both the regression fits and the observations in each county (i.e., including the county efiects estimates), models 2 or 6 are most convenient. Model 6 contains longitude, which obviously acts as a proxy for some other variable or variables; this fact does not affect its value in the prediction of radon levels in Minnesota counties, but does make it harder to compare the results of the current study to those from ather states in which longitude does not act as a useful proxy.

Model 2, which contains only NURE as an explanatory variable (and which was used to generate the predicted GMs in Table 1), still does an excellent job at fitting the county means. The estimated county geometric means are slightly less certajn than in model 6 , but the fact that only one variable is included, and that it has direct physical interpretation, may be sufficient reason to preferer this model in some instances. Note, however, that it is possible that the NURE measurement is itself partly a proxy for other important variables, as illustrated perhaps by the overlap in explanatory power between NURE and soil classes observed in previous work [Nero et al. 1994].

The models that include individual-house explanatory variables are useful for under- 
standing the factors that influence radon concentration measurements. All of the models agree that basement measurements in a county are about twice as high as first-floor measurements, and that there is no evidence that first-floor mesasurements are higher in basement homes than in non-basement homes in the same county. In addition to the models discussed in this paper, we also looked for variation of basement effect with latitude, and for a difference betwen measurements in finished and unfinished basements the magnitudes of those effects were found to be very small, and to have no significant effect on the posterior estimates for the county GMs.

Random and mixed effects regression modeling of the Minnesota radon data have proved to be extremely useful in obtaining predictions for the true county geometric mean indoor screening (i.e., short-term winter) radon measurements, and in determining the explanatory value of NURE and of the housing parameters. The predictions use all of the available datz-both measurements and explanatory variables - and take proper account of the varying number of measurements in each county. The techniques discussed in the present work allow investigation of the use of various explanatory variables to account for variations in radon measurements, while minimizing the effects of finite stanple size in the various counties.

The models seem appropriate to the data, and we have confidence in their basic conclusions; specifically, we believe the county GM estimates presented in Table 1, and their posterior intervals, to be substantially correct. We feel that the posterior estimates of the county GMs should be used rather than taking the observed GM as an estimate of the true GM: for example, it seems extremely unlikely that Lac Qui Parle county and Murray county have true screening GMs over $450 \mathrm{~Bq} / \mathrm{m}^{3}$, or even over $350 \mathrm{~Bq} / \mathrm{m}^{3}$.

The Bayesian techniques described in the current work promise more efficient use of data and more reliable prediction than other techniques currently in use in the radon characterization feld, and we recommend their more widespread use. They are particularly valuable 
when only sparse monitoring data are available; attempts to predict radon levels at smaller spatial scales such as zip code areas or census tracts will inevitably need to cope with the effects of small sample sizes. Furthermore, the statistical techniques are not specific to radon, and could profitably be applied to a wide variety of environmental problems.

\section{Notes and Acknowledgements.}

Although they are becoming a standard tool in statistics, fully Bayesian mixed effects regression computations are not currently available with commercial statistics software packages. The program we used was written in the statistics larguage " $S$ " by U.C. Berkeley statistics graduate student John Boscardin and is available on http:/stat-www.berkeley.edu/users/gelman/. The steps for a slightly more complicated version of the model are described in Section 3.2 of Boscardin and Gelman (1996); fislier discussions of such models and computation appear in Gelman et al. (1995). The program will also be part of a package of radon research tools currently being assembled by the Indoor Environment Program of the Ernest Orlando Lawrence Berkeley National Laboratory, which with be available from the lab in late 1996.

We are indebted to U.C. Berkeley graduate student John Boscardin for the use of the randorn effects regression computer program used in this work. We would like to thank Randy Schumann of the U.S. Geological Survey, Richard Sextro and Kenneth Revzan of E. O. Lawrence Berkeley National Laboratory, Deborah Nolan of the University of California, Berkeley, and Clarice Weinberg of the National Institute for Environmental Health Sciences, for their helpful comments and advice.

This work was supported by the Director, Office of Energy Research, Office of Health and Environmental Research, Human Health and Life Sciences Research Division of the U.S. Department of Energy (DOE) under contract DE-AC03-76SF00098. 


\section{References}

Alexander, B.; Rodman, N.; White, S.B.; Phillips, J., Areas of the United States with elevated screening levels of Rn222, Health Phys. 66, 50-54; 1994.

Bayes, T. (1703). An essay toward solving a problem in the doctrine of chances. Philosophical Transactions of the Royal Socjety, 330-418. Reprinted, with bibliographical note by G. A. Barnard, in Biometrika 45, 293-315; 1958.

Boscardin, W.J, and Gelman, A., Bayesian regression with parametric models for heteroskedasticjty, Advances in Econometrics 11, 87-109; 1994 .

Box, G.E.P. and Tiao, G.C. (1973). Bayesian Inference in Statistical Analysis. New York: Wiley Classics.

Bryk, A.S. and Raudenbush, S.W. (1992) Hierarchical Lineat Models, Sage Publications, Newbury Park.

Cohen, B.L., Survey of one-year average Rn levels in Pittsburgh area homes. Health Phys. $49,1053-1059 ; 1985$.

Dudney, C.S., Hawthorne, A.R., Wilson, D.L., Gammage, R.B., Indoor Rn222 in Tennessee Valley houses: seasonal, building, and geological factors. Indoor Air 2, 32-39; 1992.

Duval, J.S., Jones, W.J., Riggle, F.R., and Pitkin, J.A., Equivalent Uranium Map of the Conterminous United States, Open-File Report 89-478, U.S. Geological Survey (1989).

Gelman, A; Carlin, J; Stern, H; Rubin, D. (1995) Bayesian Data Analysis, Chapman and Hall, New York.

Gesell, T.F., Background atmospheric Rn222 concentrations outdoors and indoors: A review, Health Phys. 45, 289-302; 1983. 
Gundexsen, L.C.S., Schumann, R.R., Otton, D.E., Dickinson, K.A., Peake, R.T., and Wirth, \$.J., 1991, Preliminary radon potential map of the United States, in Procedings of the 1991 EPA International Symposium on Radon and Radon Reduction Technology, Volume 2, Symposium Oral Papers, Technical Sessions 6-10: U.S. Environmental Protection Agency Report EPA/600/9-91/037B, 9-13-9-32.

Harter, H. L. and Moore, A. H., Iterative maximum-likelihood estimation of the parameters of normal populations from singly and doubly censorẹd samples. Biometrika, 53, 205-213; 1966 .

Jackson, S.A., Estimating radou potential from an aerial radiometric survey, Health Phys. $62,450-452 ; 1992$.

Janssen, I. and Stebbings, J. H., Gamma distribution and house Rn222 measurements. Health Phys. 63, 205-208; 1992.

Lindley, D. V. and Smith, A. F. M., Bayes estimates for the linear model. Journal of the Royal Statistical Society B 34, 1-4; 1972.

Moed, B.A.; Nazarofi, W.W; Nero, A.V.; Schwehr, M.B.; Van Heuvelen, A., Identifying areas with potential for high radon levels: analysis of the National Airborne Radiometric Reconnaissance data for California and the Pacific Northwest. Bonneville Power Adminiotration DOE/BP-00098-5 (1985).

Nero, A.V.; Schwehr, M.B.; Nazaroff, W.W.; Revzan, K.L. Distribution of airbotne radon222 concentrations in U.S. homes. Science $234,992-997$; 1986.

Nero, A.V.; Gadgil, A.J.; Nazaroff, W.W.; Revzan, K.L., Indoor radon and decay products: Concentrations, causes, and control strategies; Technical Report LBL-27798, Lawrence Berkeley Laboratory (1990). 
Nero, A. V, Leiden, S. V.; Nolan, D. A.; Price, P. N, Rein, S; Revzan, K. L.; Wollenberg, H.R; Gadgil, A. J., Statistically-based methodologies for mapping of radon "actual" concentrations: the case of Minnesota Radiat. Protect. Dosim. 56, 215-219; 1994.

Price, P. N., The regression eflect as a cause of the nonlinear relationship between shortand long-term radon concentration measurements. Health Phys. 69, 111-114; 1995.

Revzan, K. L.; Nero, A. V.; Sextro, R. G., Mapping surficial radium content as a partial indicator of radon concentration in U.S. homes. Radiat. Protect. Dosim. 24, 179-184; 1988.

Schumann, R.R., Gundersen, L.C.S., Tanner, A.B., "Geology and Occurrence of Radon", Radon: Prevalence, Measurements, Health Risks and Control. Niren L. Nagda, Ed., ASTM Manual Series MNL 15, Philadelphia, PA, 1994.

Tate, E.E; Lori, A.; Pedersen, D.; Schowalter, D.; Jachim, J.; Jaros, J.; Morin, S.; Fuoss, S., Survey of radon in Minnesota homes. Minnesota Department of Health, Division of Environmental Health, Minneapolis (1988).

White, S.B.; Bergsten, J.W.; Alexander, B. V.; Rodman, N. F., Phillịs, J.L., Indoor Rn222 concentrations in a probability sample of 43000 houses across 30 states. Health Phys. 62, 41-50; 1992.

Wirth, S. National Radon Database Documentation: The EPA/State Residential Radon Surveys. Sanford Cohen and Associates, for the U.S. Environmental Protection Agency (1992).

Zeger, S. L. and Karim, M. R., Generalized linear models with random effects: a Gibbs sampling approach. Journal of the American Statistical Association 86, 79-89; 1991. 
Table 1: Comparison of GM of observations, GM predicted by ordinary regression on NURE, and posterior prediction as discussed in the text. Absolute uncertainties tend to be larger for high-radon counties than for low-radon counties. All posterior predictions and uncertainties are subject to small errors due to the finite number of simulation runs.

Table 2: Coefficient estimates and measures of model fit for models discussed in the text. Recall that coefficierts apply in transformed space, to predict the natural logarithm of the measurement (in $\mathrm{Bq} / \mathrm{m}^{3}$ ) of the indoor radon concentration. Each row includes all of the coefficients estimated for a given model, except that each model also included county dummy variables which were treated as random effects (assumed drawn from a normal distribution with mean 0 and variance $\sigma^{2}$ ). "Const" refers to the constant term in the models (where appropriate), and "long." refers to the scaled longitude variable (longitude-90)/7. 
TABLE 1

\begin{tabular}{llrrrr}
\hline county & & number & \multicolumn{3}{c}{ NURE } \\
fips & county & of & observed GM & predicted GM & posterior GM \\
code & name & obs. & $\left(\mathrm{Bq} / \mathrm{m}^{3}\right)$ & $\left(\mathrm{Bq} / \mathrm{m}^{3}\right)$ & $\left(\mathrm{Bq} / \mathrm{m}^{3}\right)$ \\
\hline 1 & AITKIN & 4 & 73 & 90 & $87 \pm 12$ \\
3 & ANOKA & 52 & 88 & 80 & $84 \pm 8$ \\
5 & BECKER & 3 & 107 & 135 & $131 \pm 18$ \\
7 & BELTRAMT & 7 & 121 & 96 & $100 \pm 13$ \\
9 & BENTON & 4 & 130 & 133 & $131 \pm 18$ \\
11 & BIGSTONE & 3 & 169 & 193 & $188 \pm 24$ \\
13 & BLUEEARTH & 14 & 250 & 178 & $194 \pm 24$ \\
15 & BROWN & 4 & 189 & 179 & $179 \pm 25$ \\
17 & CARLTON & 10 & 96 & 116 & $199 \pm 12$ \\
19 & CARVER & 6 & 144 & 157 & $153 \pm 18$ \\
21 & CASS & 5 & 151 & 95 & $100 \pm 14$ \\
23 & CHIPPEWA & 4 & 210 & 178 & $179 \pm 24$ \\
25 & CHISAGO & 6 & 107 & 87 & $88 \pm 12$ \\
27 & CLAY & 14 & 222 & 187 & $195 \pm 23$ \\
29 & CLEARWATER & 4 & 100 & 140 & $134 \pm 18$ \\
31 & COOK & 2 & 73 & 103 & $100 \pm 14$ \\
33 & COTTONWOOD & 4 & 97 & 186 & $172 \pm 24$ \\
35 & CROWWING & 12 & 97 & 94 & $95 \pm 11$ \\
37 & DAKOTA & 63 & 137 & 144 & $139 \pm 10$ \\
39 & DODGE & 3 & 224 & 177 & $179 \pm 24$ \\
41 & DOUGLAS & 9 & 194 & 164 & $168 \pm 21$ \\
43 & FARIBAULT & 6 & 75 & 181 & $156 \pm 22$ \\
45 & FLLLMORE & 2 & 105 & 197 & $187 \pm 25$ \\
47 & FREEBORN & 9 & 259 & 172 & $185 \pm 24$ \\
49 & GOODHUE & 14 & 235 & 169 & $184 \pm 23$ \\
51 & GRANT & 0 & NA & 190 & $191 \pm 27$ \\
53 & HENNEPIN & 105 & 136 & 137 & $136 \pm 9$ \\
55 & HOUSTON & 6 & 172 & 210 & $201 \pm 27$ \\
57 & HUBBARD & 5 & 85 & 110 & $105 \pm 13$ \\
& ISANTI & 3 & 107 & 86 & $87 \pm 12$ \\
& ITASCA & 95 & 92 & $93 \pm 11$
\end{tabular}


TABLE 1 (cone.)

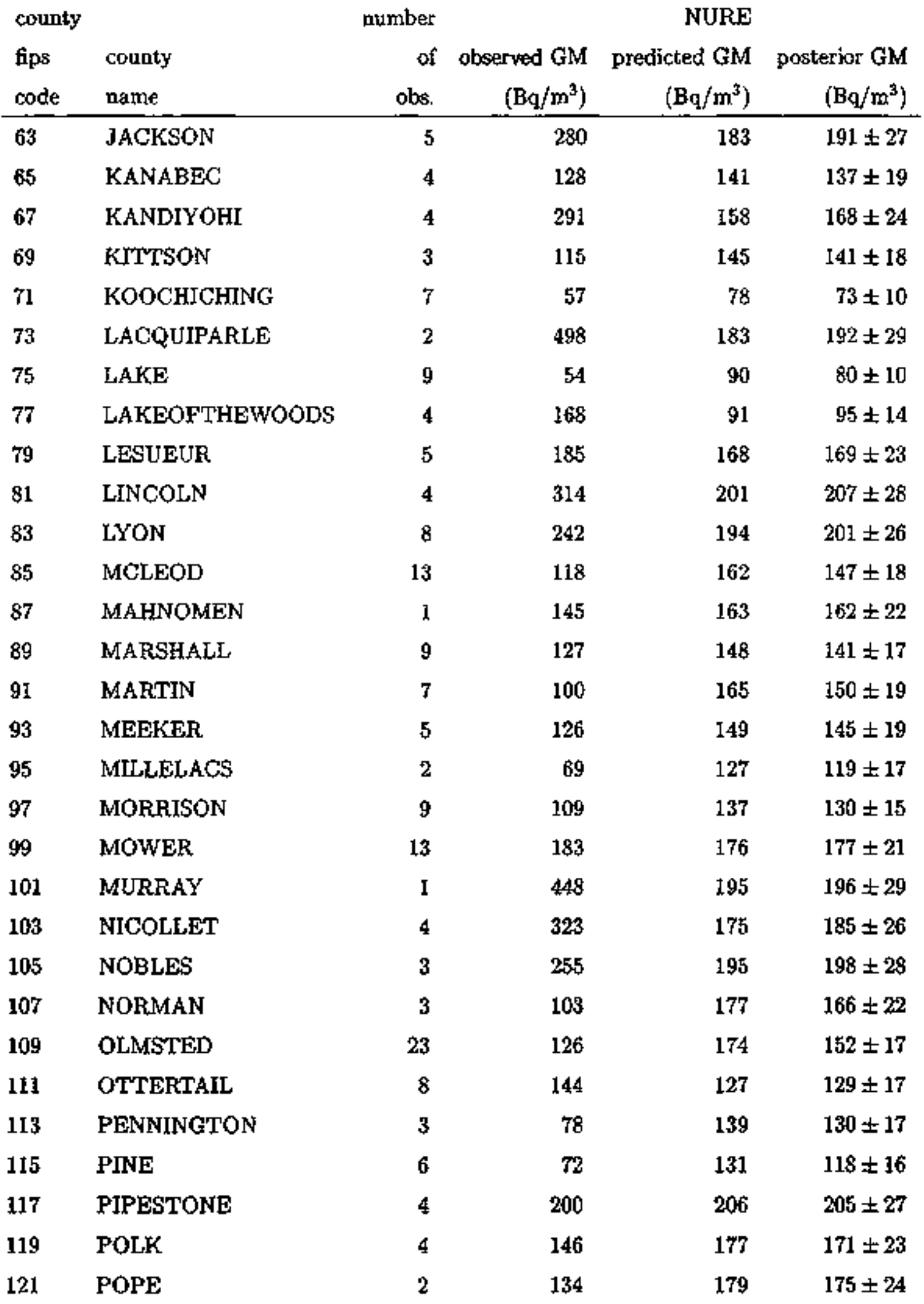




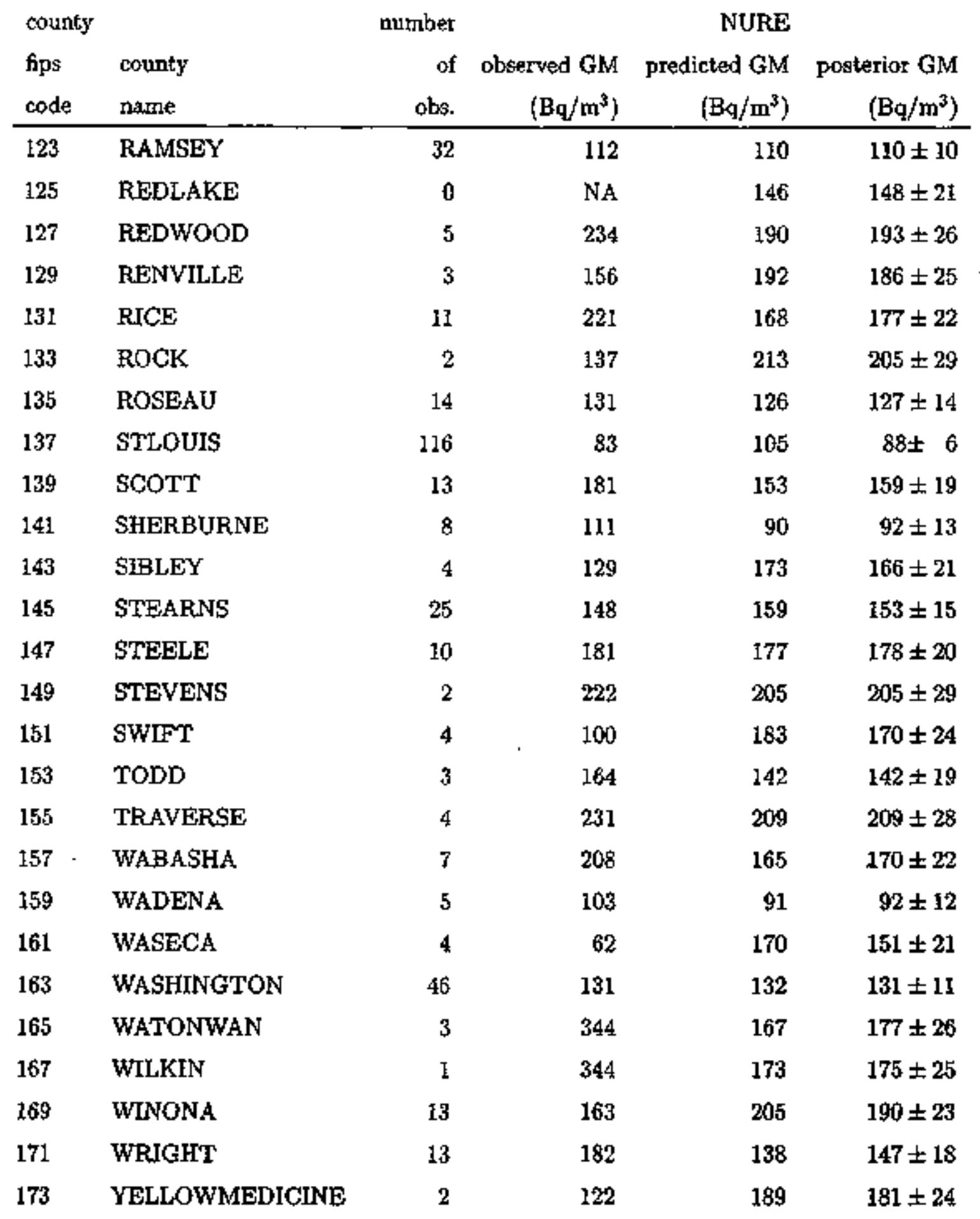


TABLE 2

\begin{tabular}{|c|c|c|c|c|c|c|c|c|c|}
\hline & \multicolumn{7}{|c|}{ coefficient estimates } & \multicolumn{2}{|c|}{ std. deviations } \\
\hline & \multicolumn{4}{|c|}{ county-level } & \multicolumn{3}{|c|}{ individual house } & & \\
\hline & & $\log$ of & fraction & & has bmt & has bmt & & & \\
\hline & const & NURE & w/o bmt & long. & meas bmt & meas 1st & no bont & $\kappa$ & $\sigma$ \\
\hline 1 & 4.86 & & & & & & & 0.76 & 0.31 \\
\hline 2 & 5.73 & 0.71 & & & & & & 0.76 & 0.14 \\
\hline 3 & & 0.70 & & & 5.85 & 5.22 & 5.22 & 0.72 & 0.17 \\
\hline 4 & 5.74 & 0.71 & -0.13 & & & & & 0.76 & 0.14 \\
\hline 5 & & 0.75 & 0.54 & & 5.87 & 5.24 & 5.19 & 0.72 & 0.15 \\
\hline 6 & 5.83 & 0.67 & & -0.32 & & & & 0.76 & 0.13 \\
\hline 7 & 5.86 & 0.63 & -0.40 & -0.41 & & & & 0.76 & 0.13 \\
\hline 8 & & 0.67 & 0.22 & -0.52 & 6.03 & 5.38 & 5.34 & 0.72 & 0.13 \\
\hline 9 & & 0.64 & & -0.55 & 6.03 & 5.38 & 5.37 & 0.72 & 0.13 \\
\hline
\end{tabular}




\section{Statewide radon concentration measurements}

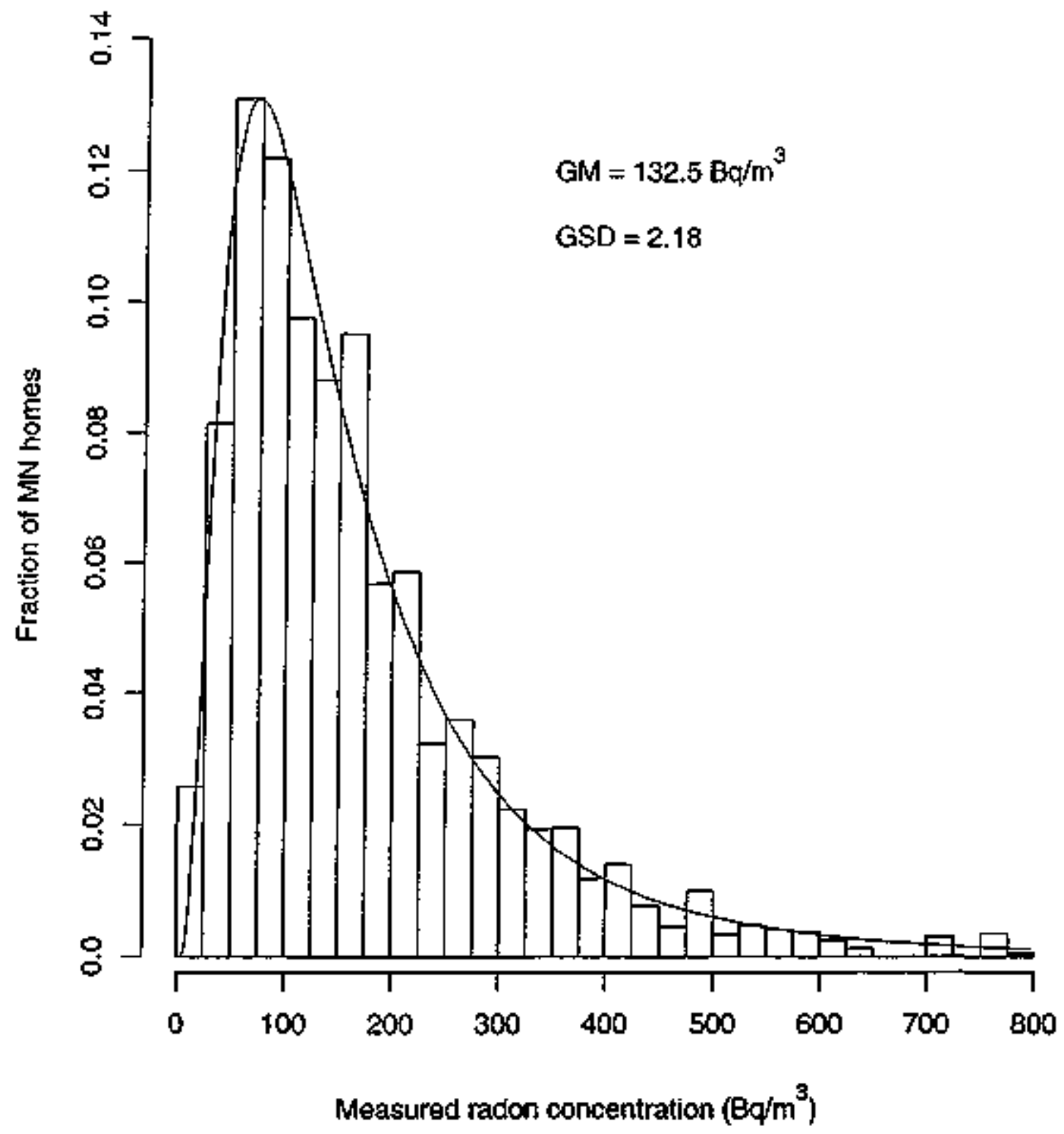

Figure 1: Histogram showing the distribution of screening radon concentration measurements in Minnesota, weighted by sampling weight reported in the SRRS data set. A lognormal distribution with $G M=132.5 \mathrm{~B} / \mathrm{m}^{3}$ and $G S D=2.18$ has been superimposed on the data. 


\section{Posterior vs. observed county GMs}

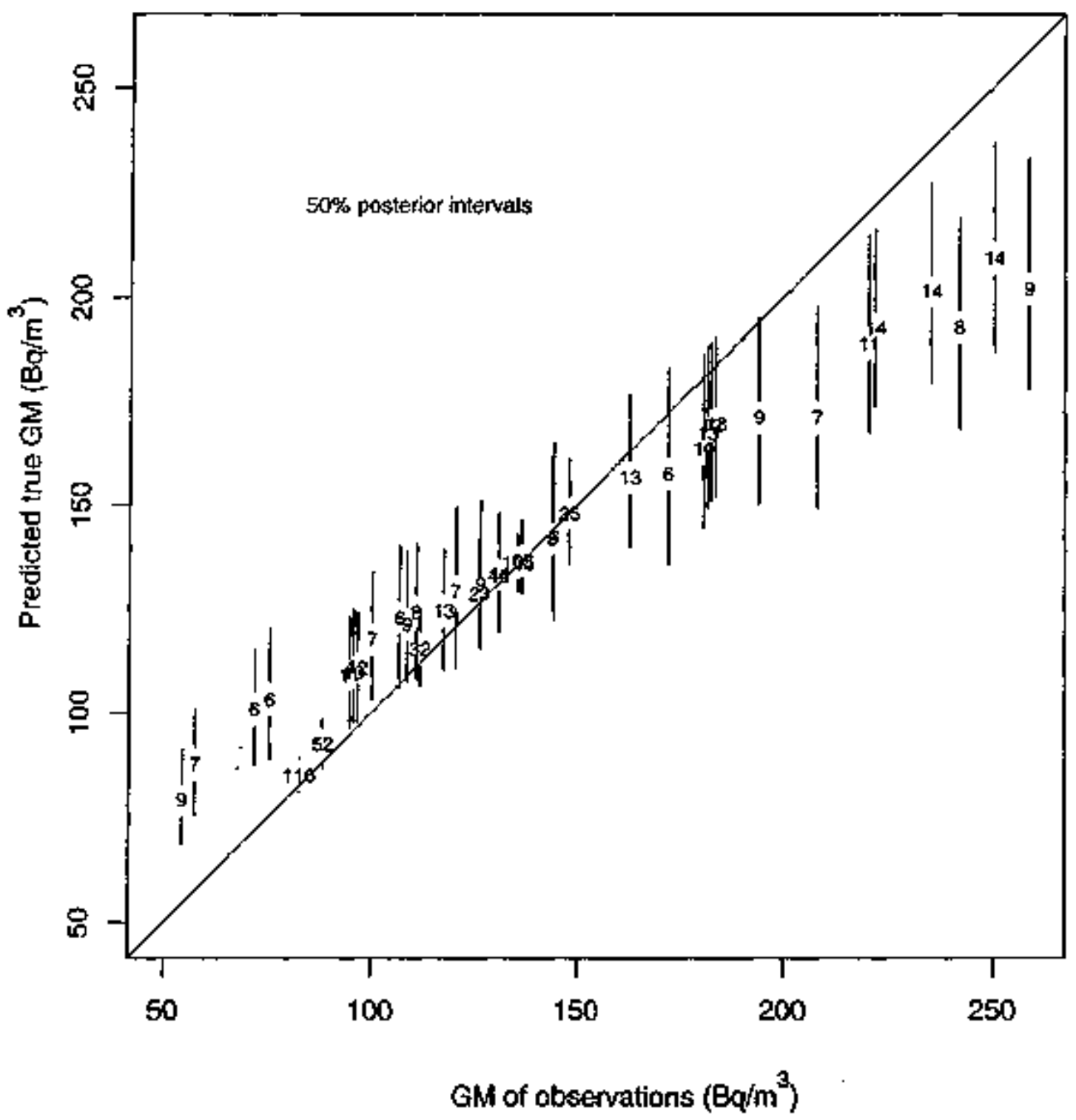

Figure 2: Posterion predictions of county GM values vs. GM of observations, for counties with more than 5 observations. Bars indicate the range that includes the middle $50^{\circ}$ of posterior predictions based on 1000 simulation draws from the probability distribution of parameter values, as discussed in the text. The posterior prediction for each county is a compromise between the observed GM in the county and the grand mean of all of the county GMs, with the relative weighting determined from the dara as described in the text. 


\section{Observed GM vs. NURE prediction}

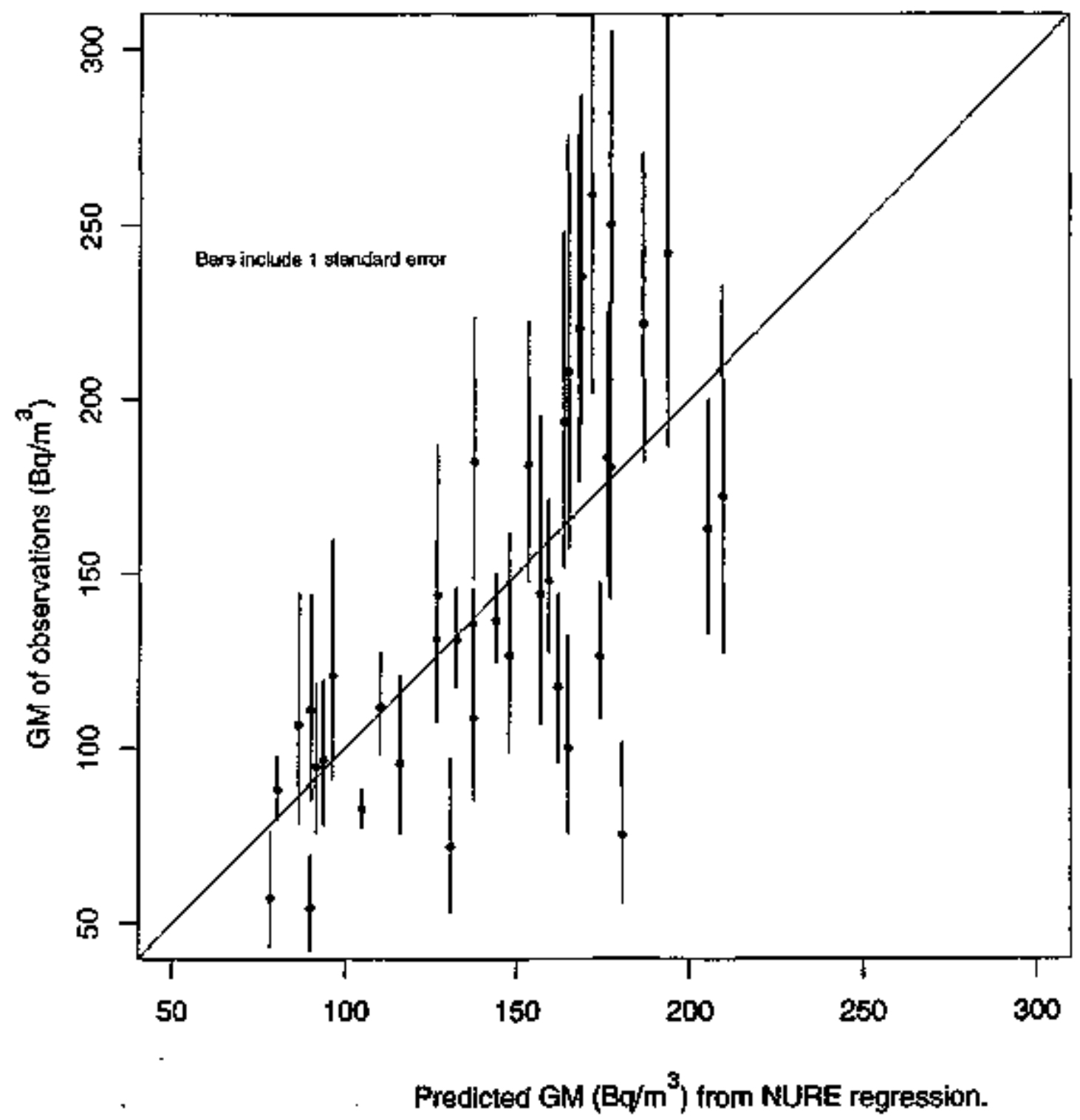

Figure 3: Results of a conventional regression of $\log (\mathrm{GM})$ on $\log (\mathrm{NURE})$, for counties with more than 5 observations. Note that more than 60\% of the error bars cross the line representing perfect agreement, and that predictions for well-sampted counties (those with small error bars) tend to fall close to the line representing perfect agreement. 


\section{Posterior Predicted County GMs}

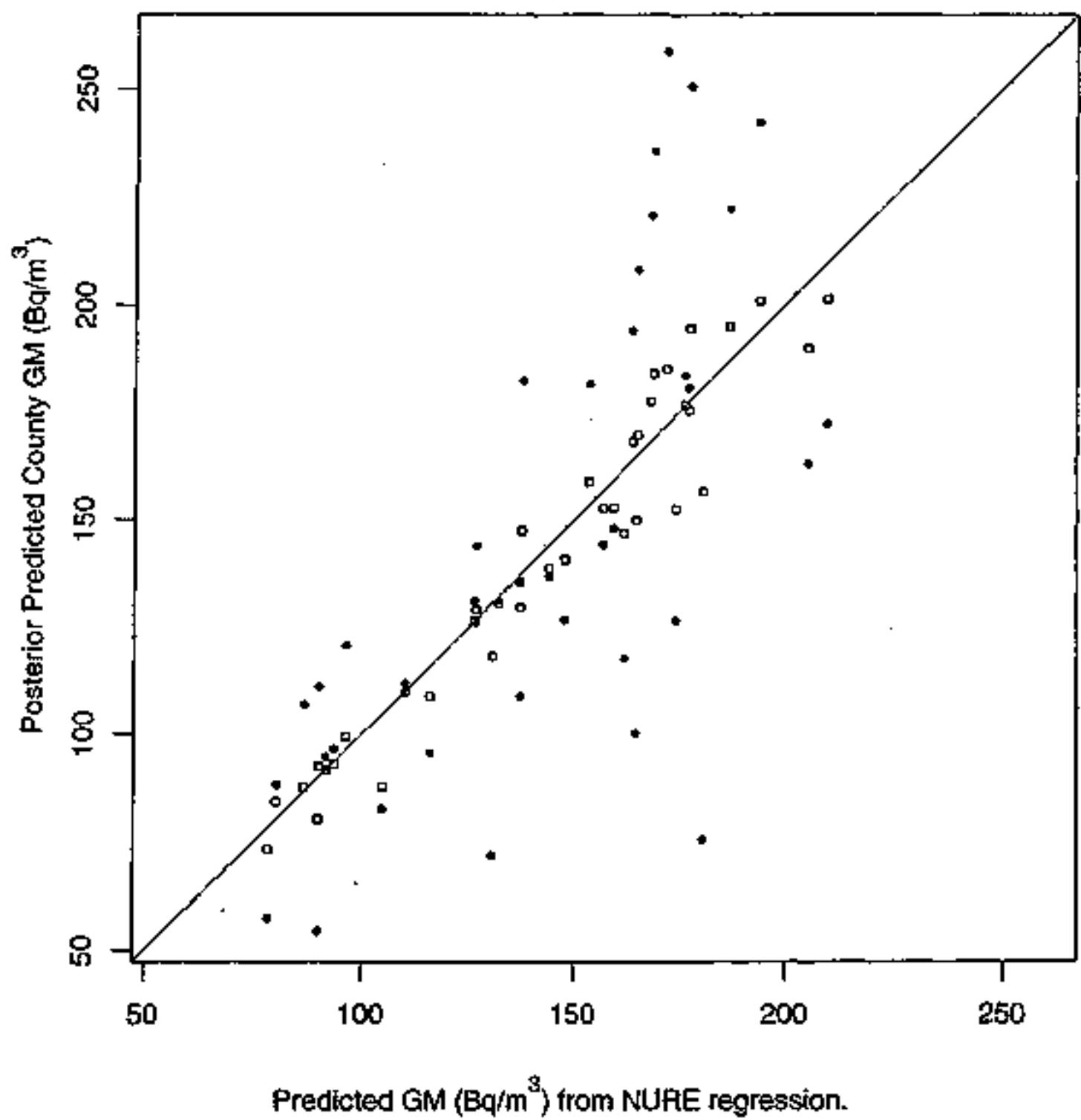

Figure 4: Results of a mixed-effects regression of logarithm of individual-house radon concentration on logarithm of county NURE and county candon effects. Only conties with more than 5 observations are sbown, although all counties were used in the analysis. Prediction from a conventional NURE regression is on the $x$-axis. Posterior predicted GMs are indicated by squares, while the GM of observations for each county is plotted as a point. Note that the posterior prediction for each county lies between the observed GM (point) and the conventional NURE prediction (45-degree line). For highly sampled counties, the posterior prediction afways lies near the observed value, while for poorly sampled counties the posterior prediction can be very different from the observed value. Posterior predictions are subject to slight variation due to the finite number of simulation draw's. 


\section{Minnesota County GMs}
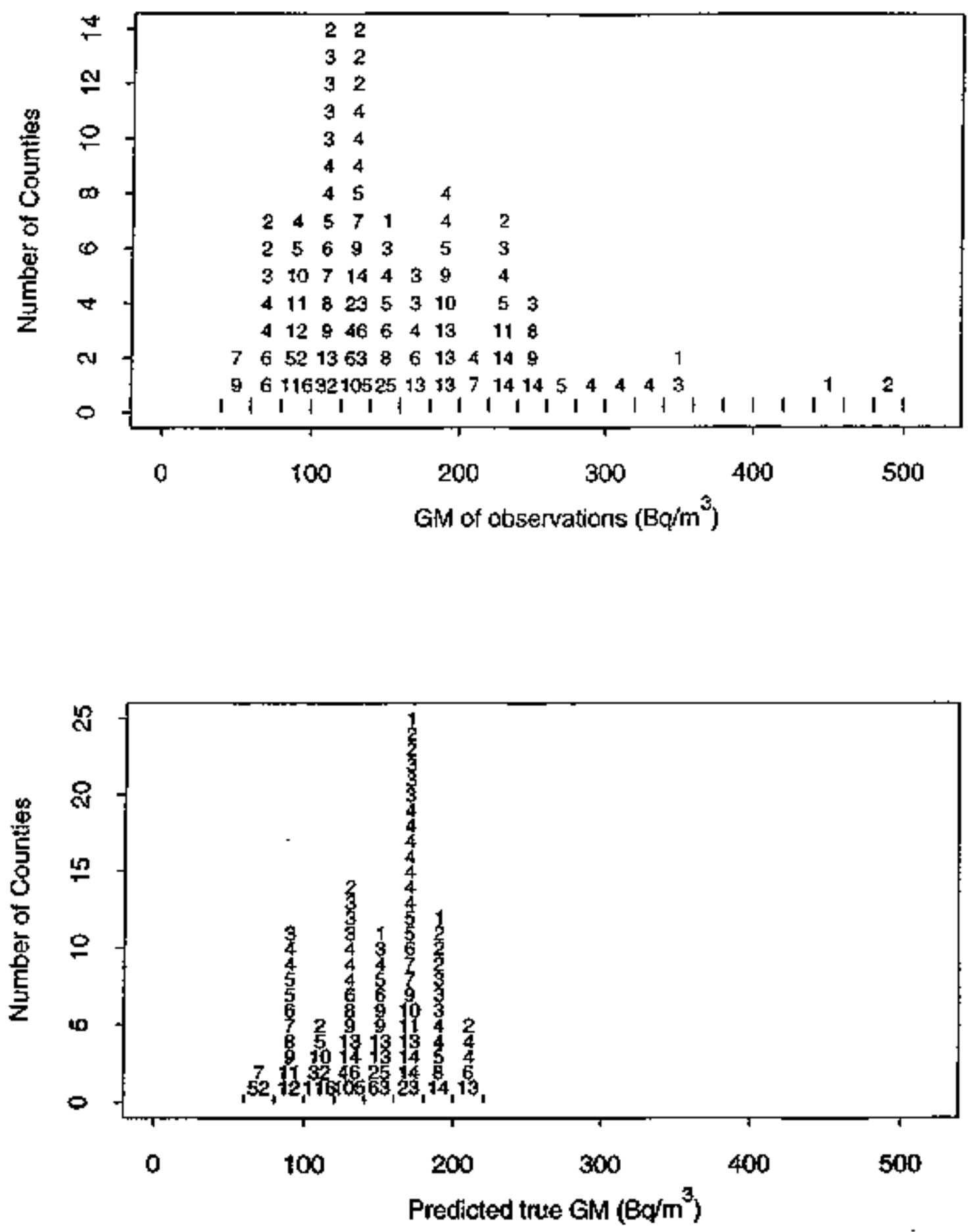

Figure 5: Stacked-number histograms showing the distribution of observed county GMs (top) and the distribution of posterior predicted GMs (bottom). Each county is represented by digit(s) indicating the number of observations in the coxinty. For example, in the upper figure the value "105" in the 120-140 Bq/ $\mathrm{m}^{3}$ interval represents a county with an observed GM between 120 and $140 \mathrm{~Bq} / \mathrm{m}^{3}$, based on 105 observations. Note that the distribution of predicted true GMs is much tighter than the distribution of observed GMs. However, recall that the predicted GMs are themselves uncertain (by about 15 to $30 \mathrm{~Bq} / \mathrm{m}^{3}$--about one bin---for most cosnties). 
Estimated model 5 county effects (times 100)

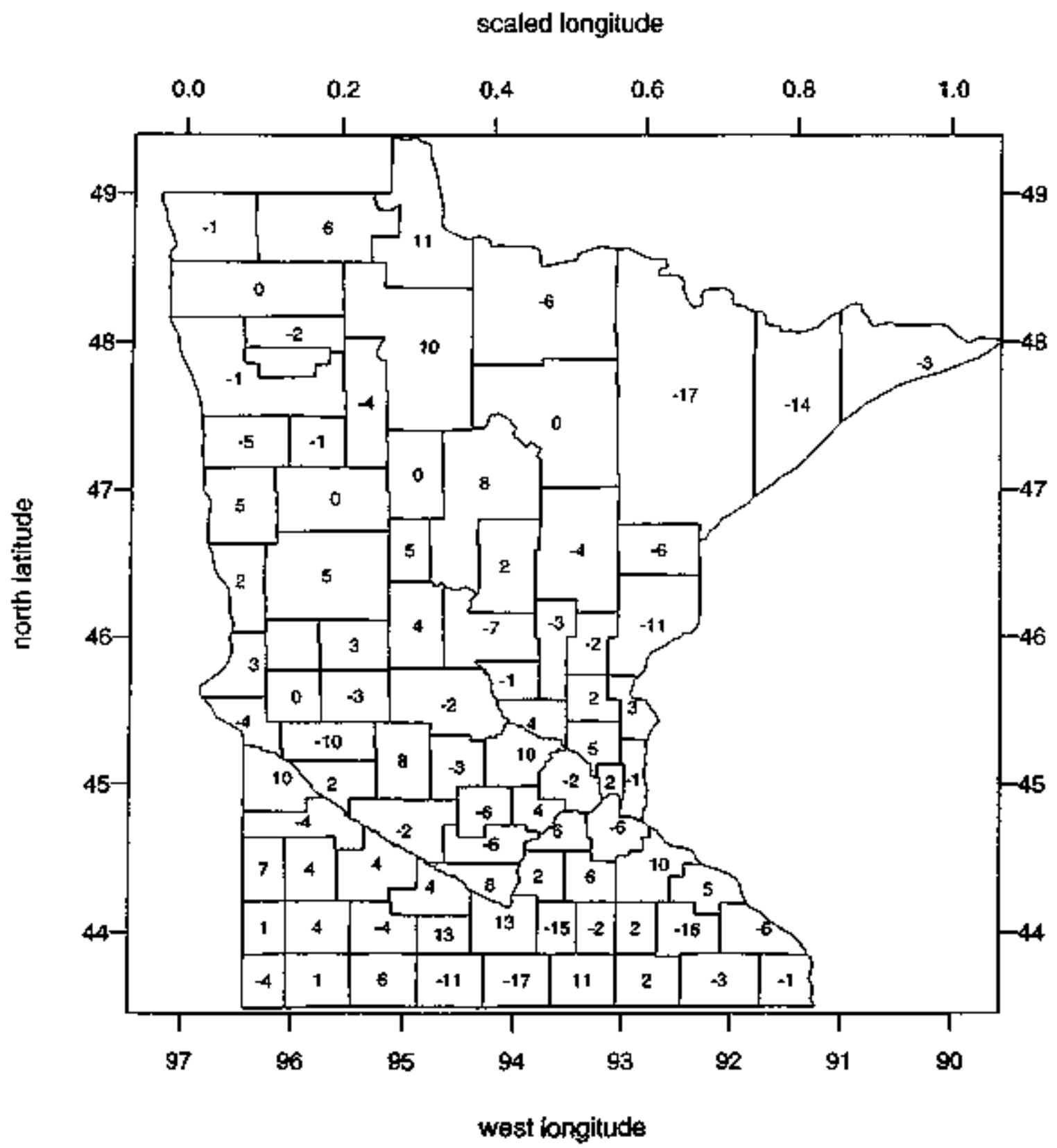

Figure 6: Map showing estimated county effects from model 5, multiplied by 100 . Note the spatial grouping of negative county effects in the northeastern portion of the state, and the sparseness of negative county effects in the western half of the state. 